\title{
Guidelines for internal Insulation of historic Buildings
}

\author{
Ernst Jan de Place Hansen ${ }^{1, *}$, Eva B. Møller ${ }^{2}$, and Morten Ørsager ${ }^{3}$ \\ ${ }^{1}$ Department of the Built Environment, Aalborg University, 2450 Copenhagen SV, Denmark \\ ${ }^{2}$ DTU Civil Engineering, Technical University of Denmark, 2800 Kgs Lyngby, Denmark \\ ${ }^{3}$ Erik Architects, 1711 Copenhagen V, Denmark
}

\begin{abstract}
Internal insulation is often the only possible solution when improving the thermal performance of solid walls of historic buildings, as many of these have architectural or cultural values. However, as internal insulation is regarded risky from a moisture perspective, guidelines are needed. The paper presents a new set of guidelines that combine written guidelines, a web-based preliminary assessment tool and a website that can be used independently of each other. The website provides simple ways of assessing the building to determine whether internal insulation is feasible in the specific case and what needs to be done before it can be applied. It also describes different failure mechanisms. The website includes links to information (written guidelines), described for different types of users, depending on their level of expertise. The web tool is based on an extensive number of simulations of hygrothermal conditions within a solid wall depending on location, orientation, wall type and thickness, and insulation type and thickness. The web tool determines the risk for mould and algae growth in a probabilistic way and determines heat loss and $\mathrm{CO}_{2}$ emission before and after renovation through $1 \mathrm{~m}^{2}$ of the wall. The guidelines, the website and the web tool are developed in RIBuild, a research project funded by the European Commission, running from 2015 to 2020.
\end{abstract}

\section{Introduction}

Internal insulation is often the only possible solution when improving the thermal performance of solid walls of historic buildings (buildings from before 1950), as many of these have architectural or cultural values. However, as internal insulation is regarded a risky way of improving the thermal performance from a moisture perspective, guidelines are needed to help building owners considering renovating historic buildings.

As building owners in many cases do not have a professional background and insight in what is decisive for a successful renovation, they need guidance at a simple level. By having such information at a website instead of a written publication, it can easily be linked to information at a more detailed level targeted at building professionals and researchers, being aware that some building owners and building professionals are more experienced that other and might need information at another level than expected. Moreover, it can improve the communication between the different partners involved in a renovation project.

The complete set of guidelines introduced in this paper is shown in Figure 1. It consists of a website introduced in section 5, written guidelines (section 3), and a webbased assessment tool (section 4). The guidelines and the web tool can be used independently of each other. The content of the guidelines is based on research reports from the European research project RIBuild (Robust Internal Thermal Insulation of Historic Buildings, www.ribuild.eu), shown in grey in Figure 1.

\section{Method}

RIBuild consists of eight work packages (WP) having five WP's delivering input to one WP (WP6) where the website, the guidelines and the web tool is developed. Input consists of data about the historic building stock, historic building materials, internal insulation systems, and experiences from case studies (WP1-WP3). Also, an efficient strategy for the probabilistic hygrothermal assessment (WP4) (further explained in section 4.2) was developed. Finally, a probabilistic methodology for assessing the environmental impacts and global costs of internal insulation solutions for historic buildings based on a life cycle perspective (WP5) was developed and implemented in a separate web tool ('Sustainability' in Figure 1).

To make this research-based outcome of the five work packages more assessable for practitioners, the work has been combined into a guideline as illustrated in Figure 1.

\section{Written guidelines}

The written guidelines consists of four parts forming a step-by-step approach: Setting the goal of the renovation, Visual assessment of the building, Selection of an internal insulation system and Evaluation of the energy saving potential.

\footnotetext{
* Corresponding author: deplace@build.aau.dk
} 


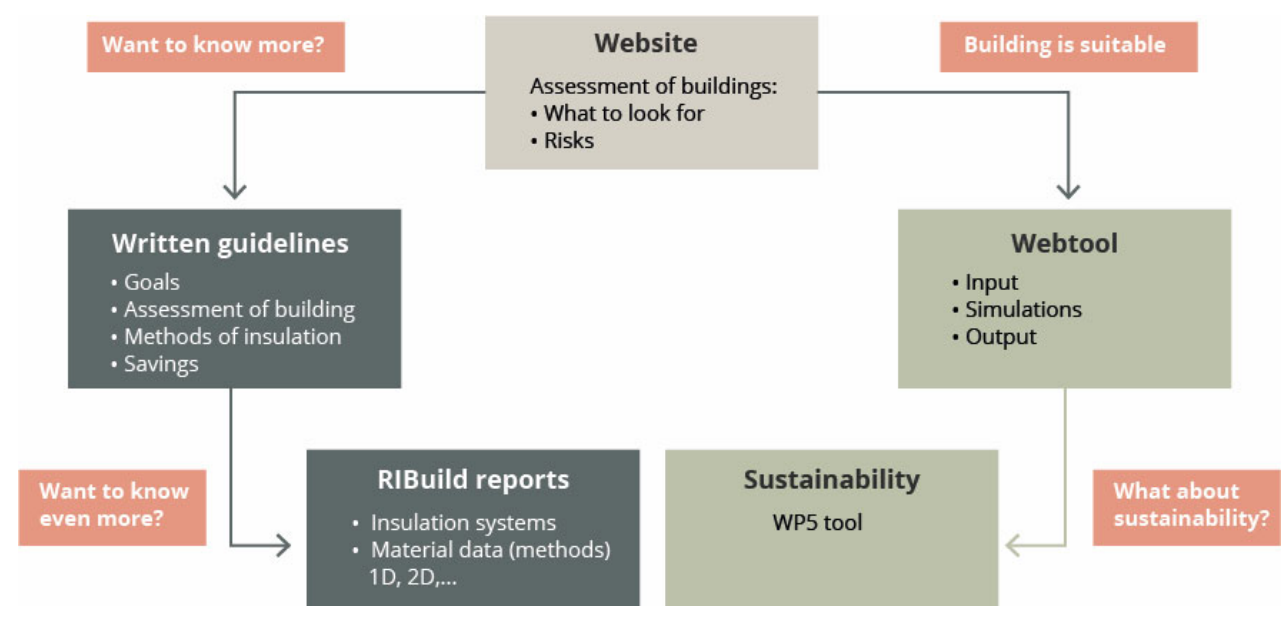

Fig. 1. Overview of content of website for written guidelines and web tool for internal insulation of historic buildings. The elements 'RIBuild reports' and 'Sustainability' are not introduced in this paper (WP = Work Package). Light grey boxes are interactive web based products, dark boxes describe reports accessible via links on the website, red boxes describe when to move to another product.

\subsection{Setting the goal}

As the first part of the guidelines, a number of possible goals for renovating a historic building is presented to the user, e.g. a building owner. This includes reduction of energy consumption, environmental impact, or energy and other costs, improvement of indoor climate, and minimizing the loss of floor area associated with internal insulation. Further, the user is introduced to national building requirements, as they might set some minimum requirements concerning energy savings, etc.

Often, the building owner sets a multitude of goals for a renovation. In the web tool presented in section 4 , the user can assign weight of each goal and the suggested insulation solutions are ranked, based on a multi-criteria analysis.

\subsection{Visual assessment}

A visual assessment of the building is given much attention in the written guidelines as detailed knowledge about the present condition of the building and its use is decisive for whether internal insulation is feasible, whether other measures should be carried out before, or whether it is too risky to apply internal insulation.

Visual assessment as a method, and what to look for is introduced, focusing on moisture related damage, as moisture is the main cause for damage in historic buildings, typically having solid external walls of brick or natural stone and floor constructions including wooden beams resting in the wall.

The assessment deals both with the present state of the building façade ('Visual assessment' in Figure 2), and with building parts where moisture damage might develop as a result of applying internal insulation ('Exposed areas'), acknowledging that hygrothermal conditions of the external wall will change as a result of this kind of renovation. This part of the assessment also deals with the importance of the driving rain load and the indoor climate, and the state of the rainwater collection system.

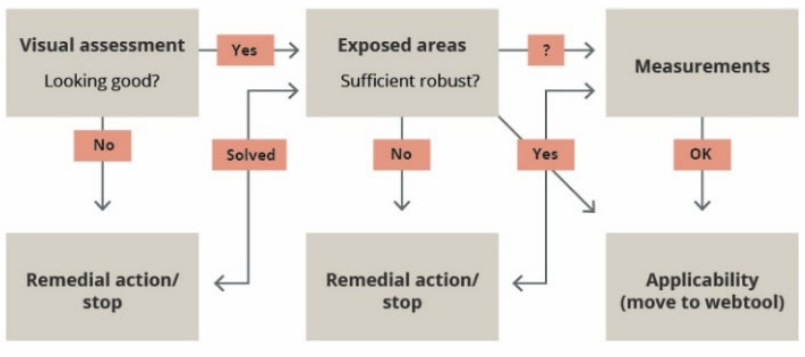

Fig. 2. Step-by-step process of assessment of a building to decide whether a building is feasible for internal insulation with or without remedial actions.

Different types of damage related to moisture are described, e.g. mould, wood rot, frost and algae. For each cause of damage, it is described what to look for and where to pay special attention, illustrated with examples as shown in Figure 3. The assessment must be made externally as well as internally, covering typical moisture problems such as leaky gutters, rising damp, thermal bridges, etc. Further, possible remedial actions are described. These are to be carried out before internal insulation can be applied.
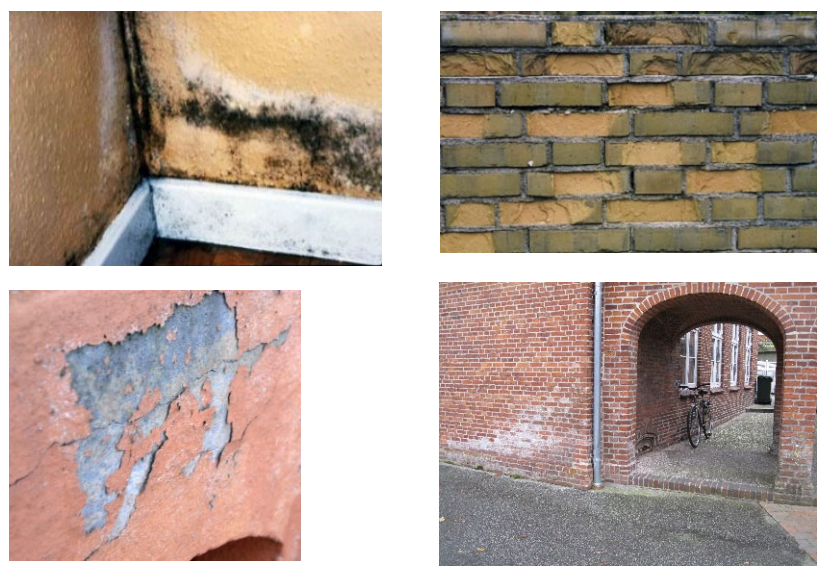

Fig. 3. Examples of visually apparent moisture induced damage of internal or external façades. From top left and clockwise: Mould growth at indoor surface, spalling due to frost, salt efflorescence, scaling of paint. 
Often a visual assessment need to be supplemented by measurements (Figure 2) to get a clearer picture of the state of the building. Descriptions of on-site and laboratory-based methods are included in the guidelines.

\subsection{Selection of internal insulation system}

Two fundamentally different insulation systems exits; vapour-tight systems including a vapour-tight layer preventing the warm, moist indoor air from penetrating the insulation, and capillary active, vapour-open systems that enables capillary suction. This is important to be aware of when considering which solution to choose in a specific building. In both cases, the behaviour of the system requires proper workmanship and proper use by the owner. Theses aspects are explained in the guidelines, e.g. the importance of ensuring a clean, dry and smooth wall in the case the insulation system is applied directly at the existing wall. The guidelines also describes the different mode of operation of the two systems in detail, including the main material parameters that characterizes these, e.g. the water vapour resistance factor.

The risks related to applying internal insulation, as its changes the hygrothermal conditions in the existing wall and adjoining building parts, might be reduced by adding a water repellent agent at the outer surface of the wall as it reduces heavily the capillary water uptake and still enables vapour diffusion [1]. The guidelines does not go into detail with the potential of combining internal insulation and water repellent agents, as the foundation for including such recommendation is still too limited. The potential benefits are at present studied in a number of projects, e.g. in Denmark and Belgium, being part of or connected to RIBuild [2], [3], [4].

\subsection{Evaluating energy saving potential}

Often renovation of a building is initiated by a high energy bill or unsatisfactory indoor climate. Therefore, it is important to assess the effect or the consequences of applying internal insulation in terms of energy saving potential and surface temperatures. From a wider perspective, life cycle cost (LCC) and environmental impact (LCA) are also important for the building owner to decide whether the goals that was set from the start (section 3.1) is fulfilled.

A separate tool was developed as part of RIBuild to perform detailed analysis of LCA and LCC with a probabilistic approach ('WP5 tool' in Figure 1) [5], [6], not presented in this paper.

In the web tool presented in section 4 , a simplified approach is implemented. The energy saving potential is based on calculations of heat loss before and after renovation. Further, LCA is calculated based on [7] and [8]. This is due to the complexity of the WP5 tool targeted at specialists, requesting user input that in most cases are very detailed. LCC is not included in the simplified approach as the output is very dependent on prices, etc.

\section{Web tool}

\subsection{Input data}

To give guidance that is more specific to the user in terms of which type of insulation system and which thickness of insulation to choose, a web-based assessment tool is being developed in RIBuild. Required user input is location, e.g. address or GPS coordinates, and orientation of the building. Further, the wall has to be described by its thickness and material (solid brickwork or natural stone) and whether the external and/or internal surfaces are plastered or not. Based on this, the web tool delivers a list of possible solutions concerning internal insulation systems.

To prioritise the possible solutions, the user may also want to describe what is the most important parameter: Uvalue, environmental impact, risk of mould growth or risk of algae growth. Furthermore, the user will be able to limit the number of solutions by specifying an interval for the thickness of the insulation and what type of insulation system that is preferred or should be avoided. This ensures that the most relevant solutions will be on top of the list. If the user for some reason does not want to use e.g. phenolic foam as insulation system or only has room for $50 \mathrm{~mm}$ insulation thickness, the list of solutions will not show results with more than $50 \mathrm{~mm}$ thickness or with phenolic foam. Figure 4 shows what input the user must give and what is optional.
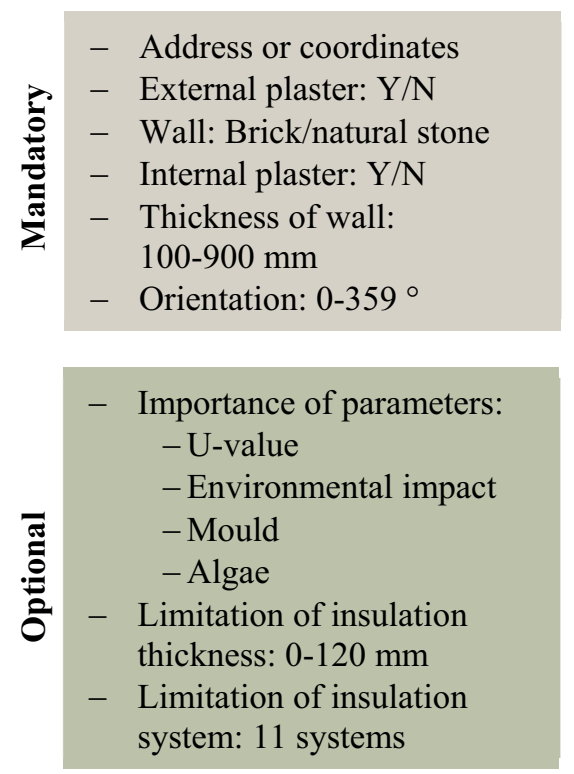

Fig. 4. User input for the web tool. Some inputs are mandatory, others are optional; the latter decide the ranking of the possible solutions.

\subsection{Basis and approach for simulations}

The web tool is based on an extensive number of simulations of hygrothermal conditions within a solid wall depending on location, orientation, wall thickness and type (brick, natural stone, with or without plaster), 
and insulation type and thickness. It makes use of databases with weather data from many European locations (www.climateforculture.eu) (Figure 5) and material properties for brick, natural stone, plaster, insulations systems etc. collected by RIBuild partners. All simulations are performed with the HAM tool DELPHIN [9].

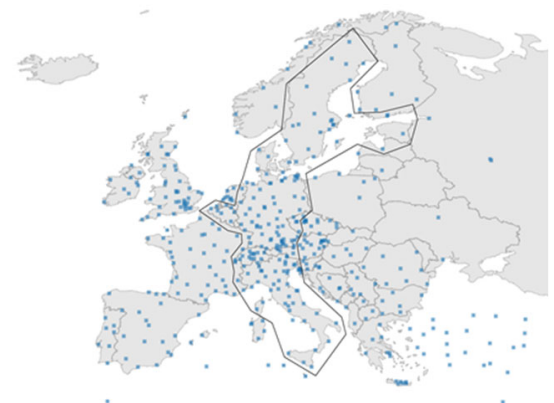

Fig. 5. European weather stations from data are collected in the Climate for Culture project (www.climateforculture.eu). The thin line marks weather stations included in the RIBuild web tool, covering RIBuild partner countries.

The web tool determines the risk for mould and algae growth using a probabilistic assessment approach and determines the heat loss and the $\mathrm{CO}_{2}$ emission before and after the renovation through $1 \mathrm{~m}^{2}$ of the wall. Frost and wood rot as failure mechanism are not included as no reliable models were identified. Besides, wood rot needs more moisture to grow than mould. The moisture and temperature threshold for mould growth based on the VTT model [10], is lower than what is expected for wood rot, therefore the mould growth threshold would be the decisive threshold, except for cases where mould may be acceptable but wood rot not.

The web tool should only be used as a preliminary assessment tool, giving an overview of possible solutions, of which analyses that are more detailed should be made by building professionals. This is due to all simulations being made in $1 \mathrm{D}$, not providing for irregularities such as thermal bridges and building details (e.g. around windows, beam ends and wall plates). They influence both the heat loss and the potential risk of moisture related damage and must therefore be assessed by professionals. 1D simulations was chosen as 2D or 3D would expand the computing time enormously. Further, it is important to recall that heat loss through the opaque façade do not cover the entire heat demand of a building. Aspects such as solar gains, ventilation losses, etc. are not included in the RIBuild web tool and guidelines, focusing on the external wall only.

A probabilistic approach was chosen to reflect that a certain risk for future damage in the external wall is present when applying internal insulation, as the input parameters for hygrothermal simulations, e.g. material properties or the driving rain load, include uncertainties, and therefore cannot be seen as fixed parameters. Furthermore, a quasi-Monte Carlo method (Sobol method) [11] has been used to reduce the number of needed simulations, opposed to simulating all combinations. Although important development concerning the numerical efficiency of a probabilistic assessment approach has been achieved within RIBuild [12], [13], it is still not realistic, that the user of the web tool would perform real-time simulations that considers uncertainties. Therefore, simulations has been done beforehand, based on choices made by RIBuild partners concerning e.g. the type of insulation systems or materials used in the existing wall. This means, the web tool will provide an answer very fast, as it is not a question of performing simulations but just sorting pre-calculated simulations. Fast response has been prioritised in developing the web tool.

\subsection{Wall types}

Although it could seem to be important which kind of brick the original wall consists of, it was concluded that the user should only be given two options; brick or natural stone. The different kind of bricks (or natural stones) were handled as a parameter with a relatively high uncertainty, representing the many different kinds of bricks or stones in the pre-calculations. This choice was based on analyses made within RIBuild, trying to identify which material parameters in bricks are the most decisive for the outcome of simulations [14]. The analyses showed that other factors such as location or orientation of the building were more important than the properties of the bricks.

Solid walls of bricks or natural stones are the most common facades in European historic buildings [15]. However, in some countries, the masonry is normally plastered externally, while in other countries bricks are in most cases left bare. When preparing an existing wall for internal insulation, the wall has to be cleaned, in some countries the plaster at the inner surface is removed as well, in others it is just cleaned. Therefore, the web tool gives the user the possibility to select whether the wall is plastered or not internally and externally.

\subsection{Output}

For each of the performed simulations, the web tool compares temperature, moisture content and relative humidity at specific locations within the wall, with threshold values for different failure modes. Based on this comparison, the risk for a certain failure is calculated, based on risk models, e.g. the VTT model for mould growth [10], and represented by a bar as illustrated in Figure 6. Further, the user should set an acceptance level for each risk. The tool does not provide a threshold value, as there are no general accepted threshold values; they may vary on a national scale or depend on the risk the specific user is prepared to take.

The red markers in Figure 6, indicating acceptance levels, are set by the user. In the example shown, any kind of heat loss reduction is regarded as sufficient, indicated by placing the red marker completely at the right $(0 \%)$. The acceptance level for algae is set much lower than for mould growth. The risk for algae growth appears to be higher than for mould growth and above the limit set by the user. Dependent on similar displays for other insulation solutions, the user will have to decide what kind 
of risk he or she is willing to take, if no solution fulfils all requirements. Figure 6 is a prototype and may be revised, e.g. risk of mould growth might be supplemented with a scale indicating Mould Index as used in the VTT model [10] as this may help the user setting the threshold.

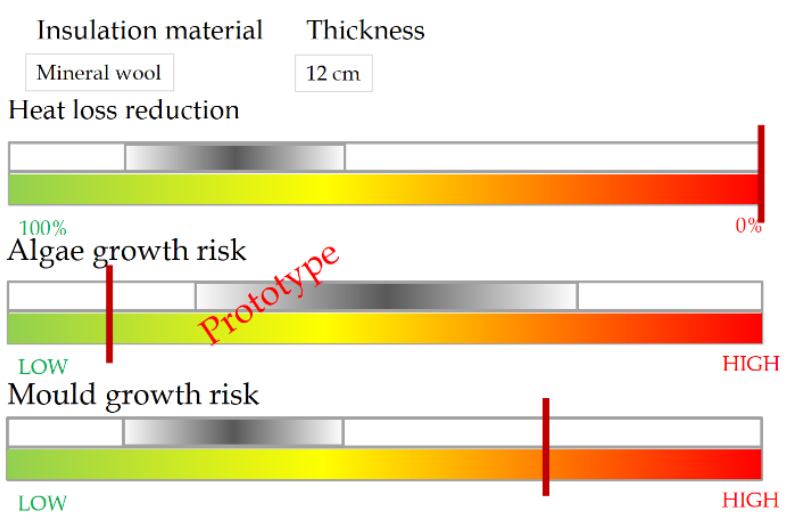

Fig. 6. Different kind of risk for failure associated with applying internal insulation. For each type of risk, a horizontal bar indicates the size of the risk. The wider the bar the more uncertain the risk. For each risk, an acceptance level is to be set by the user, represented by red markers.

\section{Website}

The website brings together the information in the written guidelines, the web-based assessment tool and the background information, as shown in Figure 1. It contains information at different levels aiming to be relevant both for building owners, architects, engineers and researchers as illustrated in Figure 7.

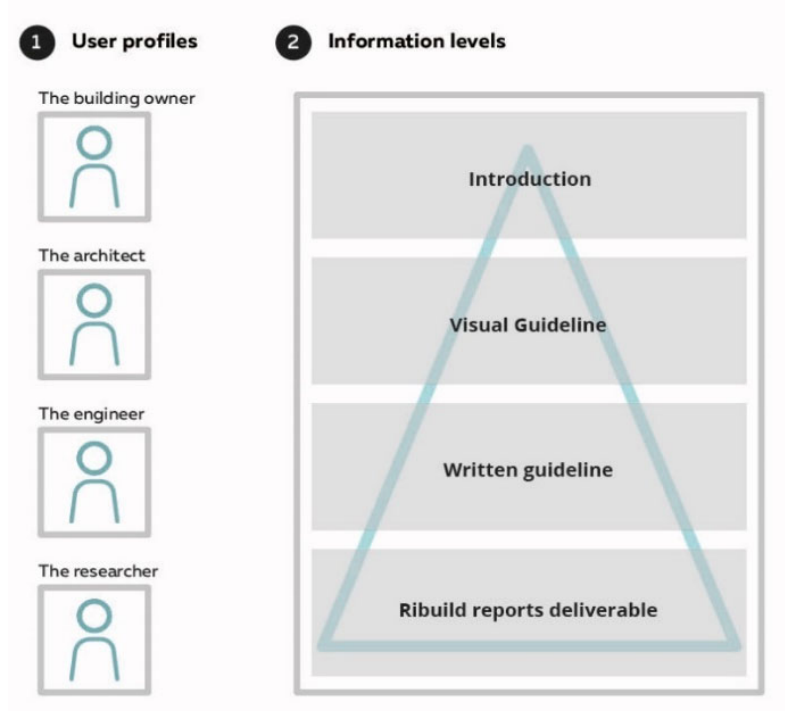

Fig. 7. By containing information at different levels and detailing, illustrated by the triangle, the website is relevant for different user profiles, having different levels of expertise.

For the user, the website is the entry point; the user will be introduced to internal insulation by a short video (Figure 8 and 9). The website also includes animated videos explaining different aspects of applying internal insulation. Figure 10 shows a screen shot from one of these, illustrating the concept of capillary-active insulation.

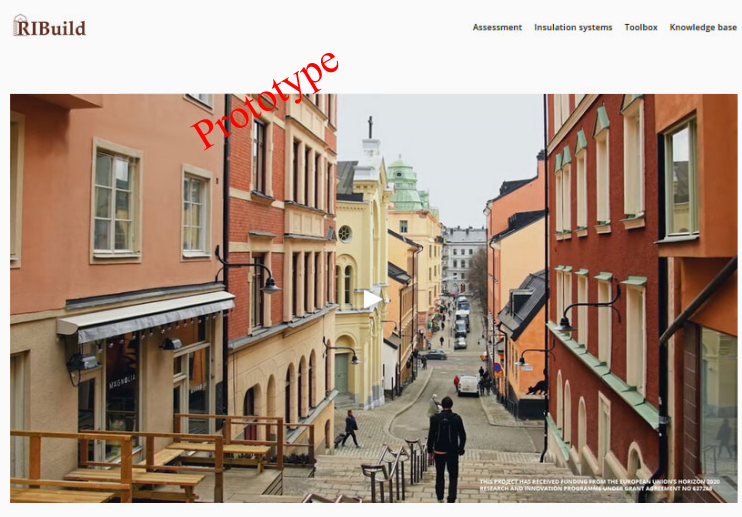

Fig. 8. Top of opening page of website (prototype); a button (at centre) can be pressed to start an introductory video .

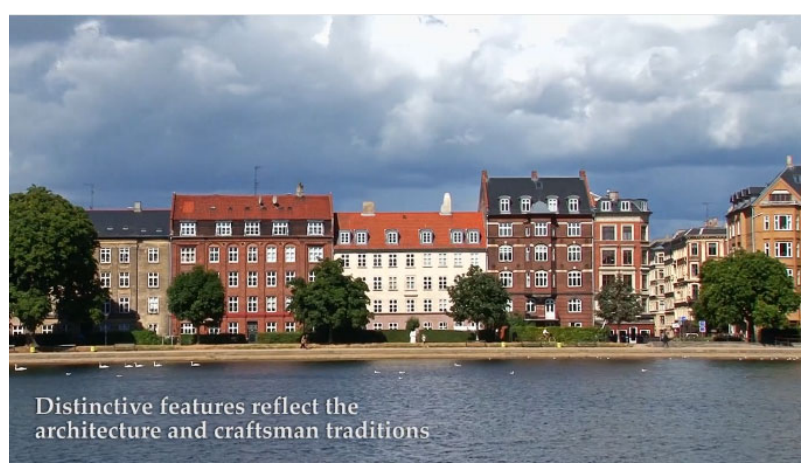

Fig. 9. Screen shot from introductory video.

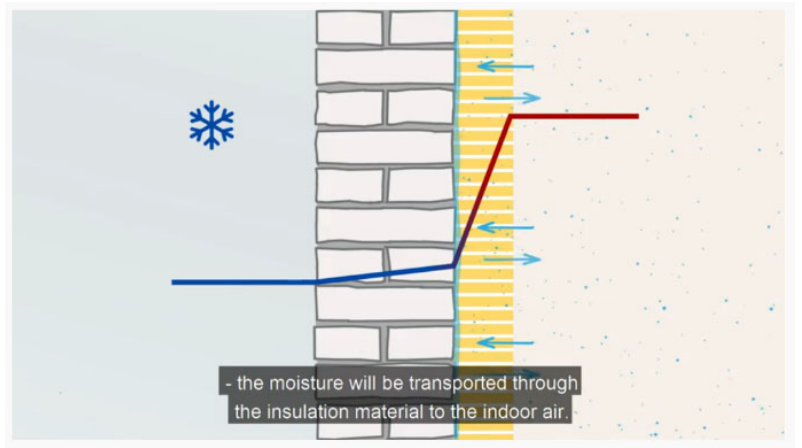

Fig. 10. Screen shot from video animation of capillary-active insulation.

Further, the user can select from a menu containing 'Assessment', 'Insulation systems', 'Toolbox' and 'Knowledge base' (Figure 11). By selecting 'Assessment' another menu opens (marked with a red box at Figure 11), where 'Risks' is chosen. This page introduces potential consequences of moisture damage, focusing on six different types of damage to look for during a visual assessment. As this is crucial to determine whether the building is suited for internal insulation or if remedial actions must be taken first. 


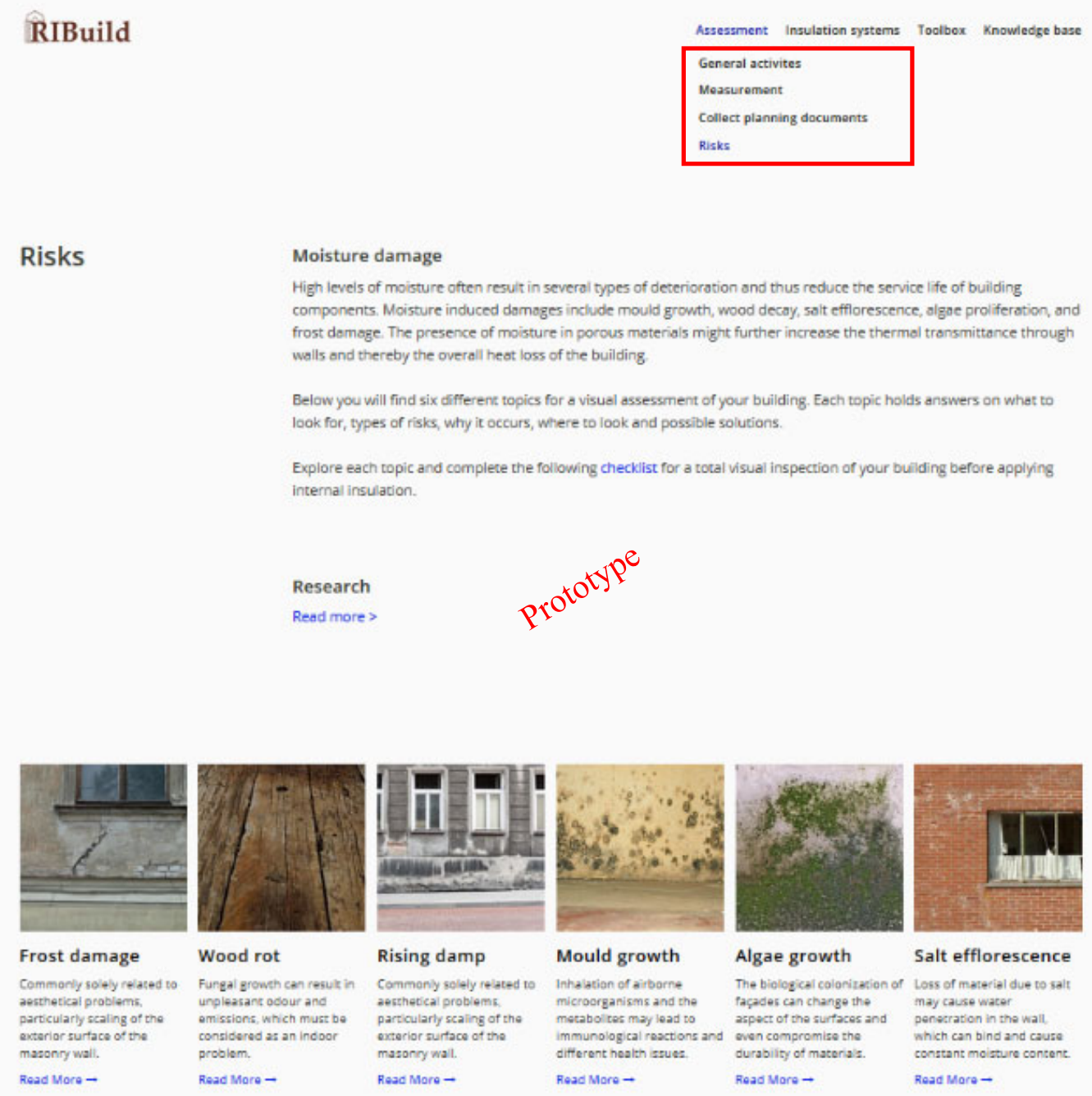

Fig. 11. Setup of website when selecting 'Assessment' at the top menu bar and then 'Risks' (prototype).

For making the visual assessment of a building as simple as possible, a setup for a mobile phone is under development (Figure 12), including check lists, referring to 'what to look for' and 'where to pay special attention' as described in Section 2.2.

Focus has been on making the website user friendly by making it informative but at the same time easy to use to collect documentation for the assessment. The different layers of knowledge gives an overview to the different user groups, making the website useful for nonprofessionals as well as professionals that are more experienced. The deep links makes it possible to find background material for the users that may have a scientific interest in the matter. However, most users will probably not go that deep.

Going from the website to the web tool will be natural for the user, the distinction made in this paper will not be clear for the user; going to the simulations will just be the next step. Some users may skip the website and go directly to the web tool. This can be acceptable, if the user is aware of the moisture related problems that internal insulation can cause.

\section{Conclusions and perspectives}

User-friendly guidelines for applying internal insulation are developed covering the stages from setting the goal for renovation to evaluating the energy saving potential. The guidelines explain at different levels of information the key points concerning internal insulation, making it useful for non-professionals as well as experienced engineers. Further, a web tool gives a list of possible internal insulation solutions reflecting the risk associated with this kind of renovation. The guidelines and the web tool as well as background information are made available through a website.

To improve the web tool, further research should be made on failure models for frost and wood rot and hygrothermal simulations should be extended to $2 \mathrm{D}$ and $3 \mathrm{D}$ to reflect the details around beam-ends, etc.

RIBuild has received funding from the European Union's Horizon 2020 research and innovation programme under grant agreement No 637268. 


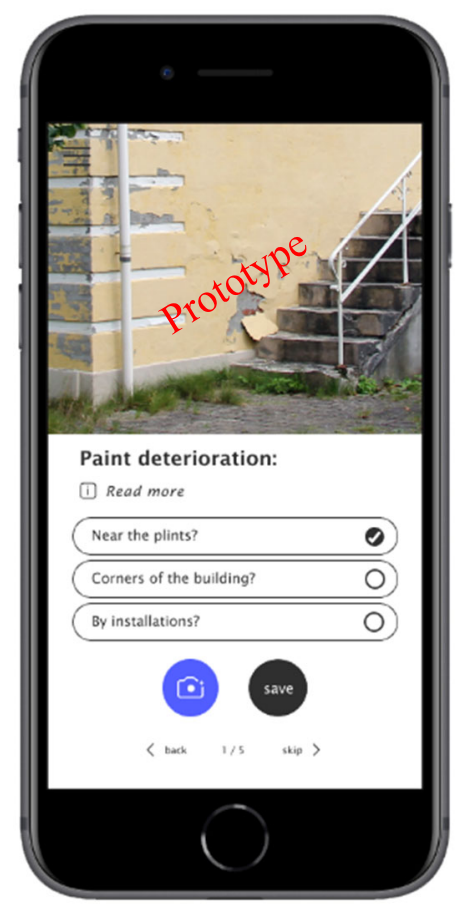

Fig. 12. Layout of checklist for on-site use on mobile phone, while performing visual assessment (prototype).

\section{References}

1. V. Soulios, E.J. de Place Hansen, C. Feng, H. Janssen, Build. Environ. (to be published)

2. H. Janssen, V. Soulios, V. Metavitsiadis, T.K. Hansen, C. Feng, D. Deckers, A. Vanek, Impact of water repellent agents on hygric properties of porous building materials (RIBuild Deliverable D2.3, www.ribuild.eu) (to be published)

3. P. Freudenberg, U. Ruisinger, E. Stöcker, S. Roels, N. F. Jensen, T. Odgaard, P. Otiv, Closed Technology Loop of Laboratory Experiments and Simulation Models in the Field of Internal Insulation Testing (RIBuild Deliverable D3.1, www.ribuild.eu) (2018)

4. T. Odgaard, S.P. Bjarløv, C. Rode, Energy \& Buildings 173 (2018)

5. E. Di Giuseppe, M. D’Orazio, C. Favi, M. Rossi, S. Lasvaux, P. Padey, D. Favre, K. Wittchen, G. Du, A. Nielsen, A. Blumberga, E. Kamendere, Report and tool: Probability based Life Cycle Impact Assessment (RIBuild Deliverable D5.1, www.ribuild.eu) (2018)

6. E. Di Giuseppe, M. Iannaccone, M. D’Orazio, S. Coderoni, E. Baldoni, R. Esposti, D. Favre, P. Padey, M. Toczé, S. Lasvaux, M. Birkved, T.K. Hansen, Report and tool: Probability based Life Cycle Cost (RIBuild Deliverable D5.2, www.ribuild.eu) (2018)

7. ISO 14044:2006, Environmental management - Life cycle assessment - Requirements and guidelines. International Organisation for Standardisation Organisation, Geneva.
8. ISO 14040:2006, Environmental management - Life cycle assessment - Principles and framework. International Organisation for Standardisation Organisation, Geneva.

9. Bauklimatik-Dresden, DELPHIN. Simulation program for the calculation of coupled heat, moisture, air pollutant, and salt transport (Technische Universität Dresden, http://bauklimatikdresden.de/delphin/index.php?aLa=en)

10. T. Ojanen, R. Peuhkuri, H. Viitanen, K. Lähdesmäki, J. Vinha, K. Salminen, Classification of material sensitivity-new approach for mould growth modeling (9th Nord. Symp. Build. Phys., pp. 867-874, 2011)

11. I.Y.M. Sobol', Zhurnal Vychislitel'noi Matematiki i Matematicheskoi Fiziki 7, 4 (1967)

12. H. Janssen, P. Freudenberg, A. Tijskens, T. Hou, Basic probabilistic analysis of hygrothermal performance of interior insulation (RIBuild Deliverable D4.1, www.ribuild.eu) (2018)

13. H. Janssen, A. Tijskens, T. Hou, Metamodelling approaches for hygrothermal performance of interior insulation (RIBuild Deliverable D4.2, www.ribuild.eu) (2019)

14. E.J. de Place Hansen, E.B. Møller, How to estimate material properties for external walls in historic buildings before applying internal insulation (3rd International Conference on Energy Efficiency in Historic Buildings (EEHB 2018), Visby, Sweden, http://eehb2018.com/conference-report/) (2018)

15. A. Blumberga, D. Blumberga, E. Kamendere, A. Kamenders, K. Kass, R. Purvins, G. Zogla, Report on historical building types and combinations of structural solutions (RIBuild Deliverable D1.1, www.ribuild.eu) (2015) 